accompanied by supraorbital neuralgia, some apparent slight paresis of the upper lid and some nasal catarrh, after a cold motor drive. By the time the author saw her every trace of abnormality had disappeared. He suspected that some mydriatic had been used, but there was no history of any drops. After further questioning Macdonald found that she had been ordered by another practitioner some liniment for a sprained knee. This was found to contain belladonna, and gave the explanation of the mysterious attack.

E. E. H.

\title{
CORRESPONDENCE
}

MERCANTILE MARINE VISION TESTS.

To the Editor of THE BRITISH JOURNAL OF Ophthalmology

SIR,-I shall be glad if you, or any reader of this Journal, will let me know what action the widowed mother of a cadet should take in order to recover the expense she has been put to in having her son trained on the training ship "Conway," under the following circumstances :-

On June 12, 1918, at Poplar, he was examined by. Board of Trade in Form and Colour Vision-Exn. 16A-and given a certificate as having "Passed" in both. On completion of his training when presenting himself for examination by a steamship Company he was rejected owing to defect of vision of one eye. This defect is due to oblique hyperopic astigmatism of one dioptre, which was no doubt present when examined at Poplar, but not detected, as the candidate assures me he was examined with both eyes open.

Norwich, October 31, 1921.

Yours faithfully, Arthur Greene.

\section{AN APHAKIC HUMAN EMBRYO}

To the Editor of The British Journal of Ophthalmology

SIR,- - In an account of a condition of aphakia in a human embryo which I gave in this Journal last summer I implied that the condition of the central nervous system in that embryo was, so far as the indifferent condition of the embryo allowed one to judge, more or less comparable with that of a normal $13 \mathrm{~mm}$. 
embryo. I have had occasion lately to examine the brain of this abnormal specimen with greater care, and I have come to the conclusion that my first impressions were not correct. The brain is there, complete, but I am convinced that the folding of its walls is not due only to collapse consequent on its condition, but that there is also some dilatation of all the main cavities of this portion of the central nervous system. The cerebral vesicles moreover, although they are quite definitely and normally apparent in their hinder parts, do not seem to be properly formed further forward, though this appearance may be partly produced by dilatation of the telencephalon. The general structure of the brain tissue seems to be quite normal for its stage. The abnormalities of the central nervous system do not seem to be very great, but I think their existence should be put on record.

Yours, etc.,

IDA C. MANN, M.B., B.S.

\section{THE INTERIM REPORT OF THE COMMITTEE OF THE MINISTRY OF TRANSPORT ON LIGHTS ON VEHICLES}

\section{To the Editor of The British JOURnal of Ophthalmologr}

SIR,-I would draw attention to the penultimate paragraph of the annotation in the present number of the Journal on the Interim Report of the Committee of the Ministry of Transport on Lights on Vehicles. The writer of the annotation says that when two motor cars approach each other with brilliant headlights it is becoming fairly general amongst motorists to turn out their headlights when passing each other so that the danger of either car running into anything during the time that the eve is regaining its dark adaptation is minimized. The real fact of the matter is that there is at present among motorists a perfect hullabaloo about the extreme danger of the present conditions, in which not only is there no definite rule as to this dimming or extinguishing, but also a wide divergence of opinion as to its advisability. It would not matter so seriously if the motorist's convenience were the only point in dispute. One may agree that the pedestrian can look after himself if he chooses to flatten himself against the hedge, but the greatest danger is to the cyclist unless he is prepared to do the same. Consider the conditions on a narrow dark road without a footpath. Two cars are about to meet with headlights on, so that the drivers, if they shade the eyes from each other's glare (which can often be done with the hand, the peak of the cap or some special device), can see everything that may be on the road. One of them extinguishes his headlights; and; as he passes the other 